\title{
IMMUNOHISTOCHEMICAL ANALYSIS OF THE MUCOSAL LESION IN MUCOCUTANEOUS LEISHMANIASIS
}

\author{
ESTERRE P.*, GUERRET S.**, RAVISSE P.***, DIMIER-DAVID L.****, DEDET J.P.**** and GRIMAUD J. A.**
}

\section{Summary :}

Using antibodies against surface antigens of inflammatory cells and against extra-cellular matrix components, immunocytochemical studies permit the investigation of the in situ cellular immune response and the associated fibrosis, in mucosal lesions. 57 paraffin embedded skin biopsies of mucocutaneous leishmaniasis originating from Bolivia, and due to Leishmania (Viannia) braziliensis, were studied. Memory T cells predominate within a non-organized granulomatous reaction, in which were observed proliferating macrophages. At the top of the lesion, epithelial cells expressed HLA-DR. Some characteristics of this lesion, particularly its chronic destructive pattern, presently lack any clear explanation.

KEY WORDS : immunology. immunopathology. pathology. mucocutaneous leishmaniasis. Leishmania braziliensis.

\section{INTRODUCTION}

1 he estimated number of leishmaniasis worldwide is now considered as surpassing 12 millions of people (Wijeyaratne, 1992). In South America, the localized cutaneous (LCL form) and the mucocutaneous leishmaniasis (MCL or "espundia") represent a severe public health problem. The MCL lesions, metastasizing from primary healed cutaneous lesions, are particularly destructive for the oral and/or nasopharyngeal cavities. Furthermore, the MCL lesions are often refractory to antimonial therapies.

During the last decade, the evolution of LCL (Ridley, 1979; Ridley, 1983; Magalhaes, 1986; Sotto, 1989; Gutierrez, 1991) and MCL (Ridley, 1980; Marsden, 1986; Ridley, 1989; Huaman, 1990) lesions has been particularly studied. The in situ analysis of cell populations and lymphokine production has been well

* Immunology Unit, Institut Pasteur de Madagascar, BP1274, Antananarivo, Madagascar.

** Molecular and Cellular Pathology Unit for Tissue Fibrosis, CNRS URA 1459, Institut Pasteur de Lyon, F-69365 Lyon Cédex 07, France.

**** Histopathology Unit, Institut Pasteur, F-75235 Paris cédex 15, France.

**** Parasitology Lab., Instituto Boliviano de Biologia de Altura, La Paz, Bolivia.

Corresponding author: Dr. J.P. Dedet, Laboratoire d'Écologie Médicale et de Pathologie Parasitaire, Faculté de Médecine, 163 rue A. Broussonet, F-34059 Montpellier cédex, France. Tél. 67336960 67632751 - Fax 67630049
Résumé : ANALYSE IMMUNOHISTOChimique DE LA LÉSION MUQUeUSE AU COURS DE LA LEISHMANIOSE CUTANÉO-MUQUEUSE

Cinquante sept biopsies de lésions muqueuses de leishmaniose cutanéo-muqueuse à Leishmania (Viannia) braziliensis, originaires de Bolivie, ont été incluses en paraffine. Ces biopsies ont fait l'objet d'une analyse immunohistochimique, les objectifs étant de caractériser l'infiltrat cellulaire et le tissu conjonctif. Dans l'infiltrat inflammatoire muqueux, on a observé la présence de lymphocytes T "mémoire" distribués au sein d'un granulôme riche en macrophages qui prolifèrent. En superficie de la lésion, les cellules épitéliales sont positives pour HLA-DR. Certaines particularités de cette lésion, plus particulièrement la destruction tissulaire, ne sont pas clairement explicables à l'heure actuelle.

MOTS CLES : immunologie. immunopathologie. anatomo-pathologie. leishmaniose cutanéo-muqueuse. Leishmania braziliensis.

documented in LCL (Castes, 1983; Carvalho, 1985; Magalhaes, 1986; Modlin, 1989; Pirmez, 1990; Esterre, 1992), but less in MCL. In this last pathology, the immune response has been characterized in the peripheral blood (Carvalho, 1985) and at the T lymphocyte level (Pirmez, 1990). The tissular and peripheral $\mathrm{T}$ cell populations are significantly different (Modlin, 1985; Pirmez, 1990). But the histopathological approach revealed other cellular events, such as in situ macrophage differentiation, plasma cell infiltration, extra-cellular matrix remodeling and specific vascular changes (Sotto, 1989; W.H.O., 1990). This study examines in situ the macrophage phenotype and its topography within the lesions, and the associated tissue remodeling, in order to obtain new findings on the pathogenesis of this mucosal lesion. We analysed in more detail, by immunohistochemistry, the well-documented collection of material previously studied with an histopathological approach (DimierDavid, 1994).

\section{MATERIAL AND METHODS}

$\mathrm{F}$ ifty-seven biopsies of MCL lesions were taken from Bolivian patients, with leishmaniasis confirmed by the laboratories of the IBBA, La Paz. The disease was related to Leishmania (Viannia) braziliensis, by isoenzyme electrophoresis of parasite culture isolates. The histological analysis 


\begin{tabular}{|c|c|c|l|c|}
\hline Antibody & Cluster* & Isotype & \multicolumn{1}{|c|}{ Specificity } & Source** \\
\hline PD7/LB11 & CD45 & IgG1 & Leukocyte Common Ag & Dako \\
L26 & CD20 & IgG2a & B Lymphocytes & Dako \\
A452 & CD3 & (Rabbit) & mature T lymphocytes & Dako \\
DFT1 & CD43 & IgG1 & T lymphocytes, some myeloid cells & Dako \\
TAL1B5 & $/$ & IgG1 & HLA-DR & Dako \\
OPD4 & CD4 & IgG1 & helper T subset & Dako \\
Mac387 & $/$ & IgG1 & Histiocytes & Dako \\
KP1 & CD68 & IgG1 & Monocyte/macrophages & Dako \\
PGM1 & CD68 & IgG3 & Monocyte/macrophages & Dako \\
NP57 & $/$ & IgG1 & Neutrophil elastase & Immunotech \\
JC/70A & CD31 & IgG1 & Endothelial cells, platelets \\
BNH9 & $/$ & IgG1 & Endothelial cells & Dako \\
F8/86 & $/$ & IgG1 & Endothelial cells, Megakaryocytes & Dako \\
S100 & $/$ & Rabbit & Dentritic cells & Dako \\
PCNA & $/$ & IgG2a & Proliferating cells & \\
\hline
\end{tabular}

Table I. - Characteristics and specificity of the antibodies used in this study * Clusters of differentiation (CD) established at the 4th Workshop on Human Leukocytes Antigens, Vienna, Austria, 1989. ** Dako, Dako France SA, Trappes, France.

Immunotech, Marseille-Luminy, France.

\begin{tabular}{|l|c|c|c|}
\hline & Normal epithelium & $\begin{array}{c}\text { Perilesional } \\
\text { fibrotic matrix }\end{array}$ & $\begin{array}{c}\text { Inflammatory } \\
\text { granuloma }\end{array}$ \\
\hline Collagen isotype I & ++ & ++ & + \\
Isotype III & ++ & ++ & ++ \\
Isotype IV & ++ & ++ & + \\
Fibronectin & + & ++ & + \\
Laminin & ++ & + & - \\
Elastin & ++ & & + \\
\hline
\end{tabular}

Table II. - Extra-cellular matrix proteins expressed in the lesion of mucocutaneous leshmaniasis (indirect immunofluorescence technique)

of each biopsy, fixed in formaldehyde solution, was performed with haematoxylin and eosin (H\&E) staining in a reference laboratory (Histopathology unit, Institut Pasteur). Immunohistochemistry was made on $5 \mu \mathrm{m}$ section with the labelled streptavidin-biotin method (LSAB kits, Dako France, Trappes) and a semi-automatized staining station (Sequenza workstation, Shandon Scientific, Runcorn, UK). A panel of 14 antibodies, described in table I with their specificity and origin, was used in this study.

Morphometric data on fibrosis extent were obtained on Picrosirius red stained sections, using an automatic image analysis system (Biocom 200, Biocom, France). The ratio fibrous area/section area was automatically calculated in each section, and the results are expressed as the mean value of 10 sections. The different extra-cellular matrix components were identified by indirect immunofluorescence, using the following chromatography-purified antibodies developed in our laboratory (Esterre, 1991) : they bind to collagen isotypes I, pro-III, III and IV, elastin, laminin and fibronectin.

Two biopsies of individuals undergoing surgical excision of a nasal polyp were used as control biopsies. Their histological examination reveals weak inflammation without any epithelium alteration.

\section{RESULTS}

T lymphocytes, most of them expressing CD4, greatly predominate over B lymphocytes in the lesion. As expected (Pirmez, 1990), an increase of memory (CD45RO+) $\mathrm{T}$ cells has been noticed with the UCHL1 marker (Dako lab.), but this preliminary result on paraffin material must be confirmed on a larger sample of frozen biopsies. Resident macrophages (Mac 387+, HLA DR-), described as histiocytes 
on conventional pathological examination, were observed admixed with activated macrophages (Mac 387-, HLA DR+, fig. 4), lymphocytes and fibroblasts. No special topography suggesting an epithelioid pattern could be observed in our sample (fig. 2), but some of the macrophages were immunostained by the PCNA marker (fig. 3). The macrophages were rarely infected, but we observed some of them with many intracellular amastigotes (fig. 1). No extracellular amastigotes could be identified. The immunostaining with the anti-HLA DR antibody enabled the detection of positive epithelial cells at the top of the inflammatory reaction (fig. 4).

The morphological data obtained with the endothelial cell markers (fig. 5) were quantified by image analysis, in which the vessels morphometric size variables were statistically different between mucosal and skin lesions. Furthermore we noticed a frequent periarteritic fibrosis in some MCL lesions. In the inflammatory areas, the mean values of fibrosis extent in the mucosal lesion of MCL (13.2 $\pm 4.6 \mathrm{p}$. cent of the area) are in line with that calculated in the cutaneous lesion of MCL $(20.1 \pm 11.3 \%)$ and LCL $(19.1 \pm 10.1 \%)$. In the fibrotic periinflammatory areas, this proportion is increased in the mucosal lesion $(49.3 \pm 14.6 \%)$ as compared with the cutaneous lesions of MCL and LCL (26.1 $\pm 11.1 \%$ and $27.3 \pm 5.1 \%$, respectively).

By immunofluorescence (table II), the extra-cellular matrix components were found to include collagen type I and III, fibronectin and laminin. No elastin was detected in this sample, as with the LCL lesion (Esterre, 1991).

\section{DISCUSSION}

The local accumulation of effector molecules and immunocompetent cells (Allardyce, 1984; Gutierrez, 1991; Brandtzaeg, 1992; Kuper, 1992; McGhee, 1992) is important in the resistance to mucosal infections. But we have, actually, only speculative explanations for the chronic destructive features occuring in the MCL lesion. In vitro studies of the immunologic responsiveness in MCL patients suggest a status of hyperactive immune response (Castes, 1983; Pirmez, 1990). A preliminary in vivo analysis revealed a predominant $\gamma \delta \mathrm{T}$ memory $(\mathrm{CD} 4+\mathrm{CD} 45 \mathrm{RO}+)$ delayed type hypersensitivity reaction (Pirmez, 1990), with no increase of $\gamma \delta \mathrm{T}$ lymphocytes by opposition with the results obtained on LCL lesions (Modlin, 1989; Esterre, 1992). In our opinion, T cells have a potential role in the early LCL lesions (Esterre, 1991), where a non-specific inflammatory reaction occurs, but not in more chronic stage such as old LCL and MCL lesions (Pirmez, 1990). As far as this hypothesis is true, the
MCL lesion can be considered as a "delayed" (Ridley, 1989) or "disorganized" (Pirmez, 1990) granulomatous reaction. Although tissue macrophages are one of the most important cell population in the human airways (Juliusson, 1991), their potential role has not been studied in detail in the MCL lesion. In the present study the immunophenotyping and the topography of macrophages was analysed in the mucosal lesion. No epithelioid organisation could be clearly demonstrated, supporting the previous hypothesis, as the presence of a non negligible in situ proliferation (probably revealing recently recruited monocytes). The nature of chemokines/adhesive molecules leading to the recrutement of $\mathrm{T}$ lymphocytes within MCL lesions remains poorly defined. S100 + dentritic cells, alone or in addition to tissue macrophages, might play such a role. The topography of vessels within MCL lesion seems to indicate that a strong neo-angiogenesis occurs in MCL lesion by comparison with the LCL lesion. Future characterization of site-specific epitopes expressed on inflammatory lymphocytes (such as HECA-452 and MLA for skin-homing and mucosalhoming lymphocytes, respectively) and their corresponding vascular addressins might be highly informative. The periarteritic fibrosis process which develops in MCL lesion remains unexplained.

In contrast to the observations made in New World LCL (Huaman, 1990; Esterre, 1991) and MCL (Ridley, 1980; Ridley, 1983; Ridley, 1989), the involvement of a connective tissue reaction is considered to be insignificant in Old World LCL (Ridley, 1979). The fibrotic process has been linked to a good prognosis (Ridley, 1980; Ridley, 1989; Huaman, 1990 ; Gutierrez, 1991), in contrast to the macrophage lysis and the associated tissue necrosis (Ridley, 1989). We must remember that the alterations observed are identical in the different mucosae concerned by this disease (Dimier-David, 1994). More investigations on the in situ cytokine network and the nature of enzymes are needed before understanding the evolution of the MCL lesion as well as the nature of factors predisposing to mucosal metastasis of Leishmania in the early phase of MCL development (Gutierrez, 1991).

\section{ACKNOWLEDGEMENTS}

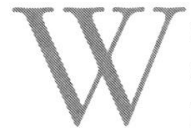
e wish to thank Hugues Lortat-Jacob (CNRS URA 1459, Lyon) and Dominique Kaizerlian (INSERM U80, Lyon) for helpful scientific discussion. We are also grateful to Gérard Joly (CNRS URA 1459) for help with the photographic documents. 

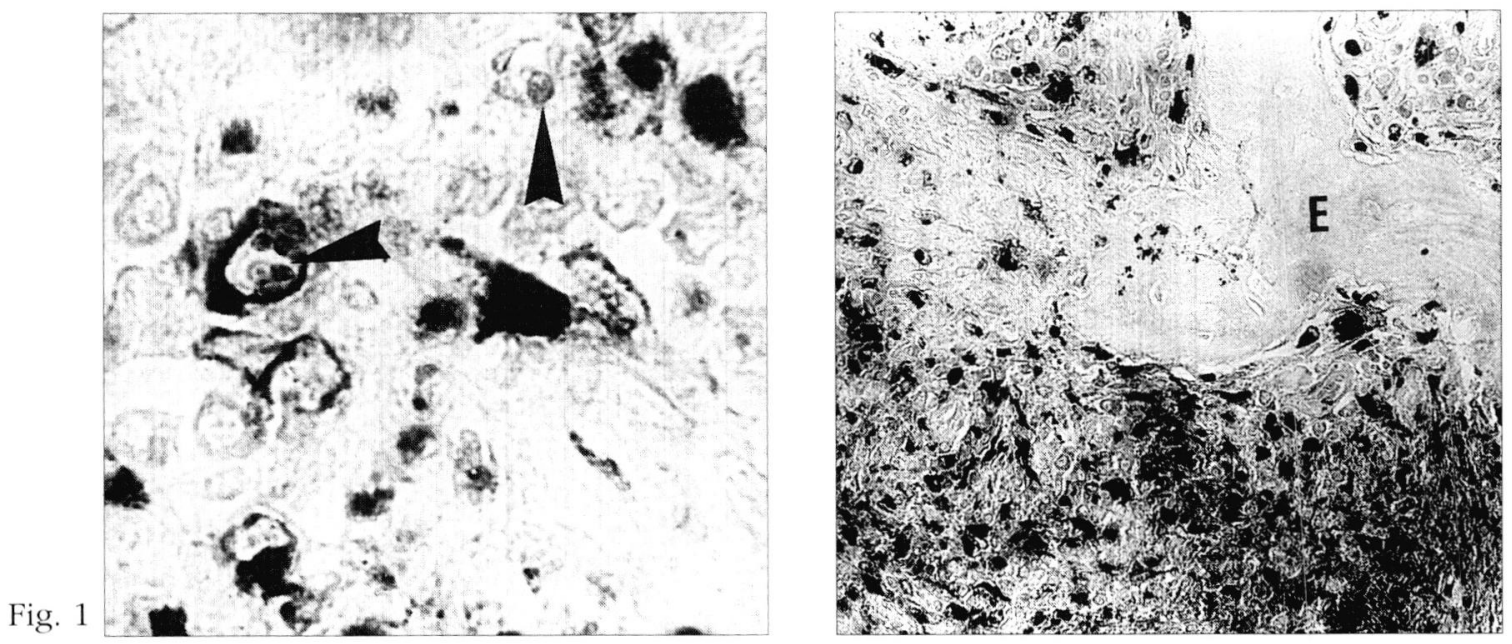

Fig. 2

Fig. 3
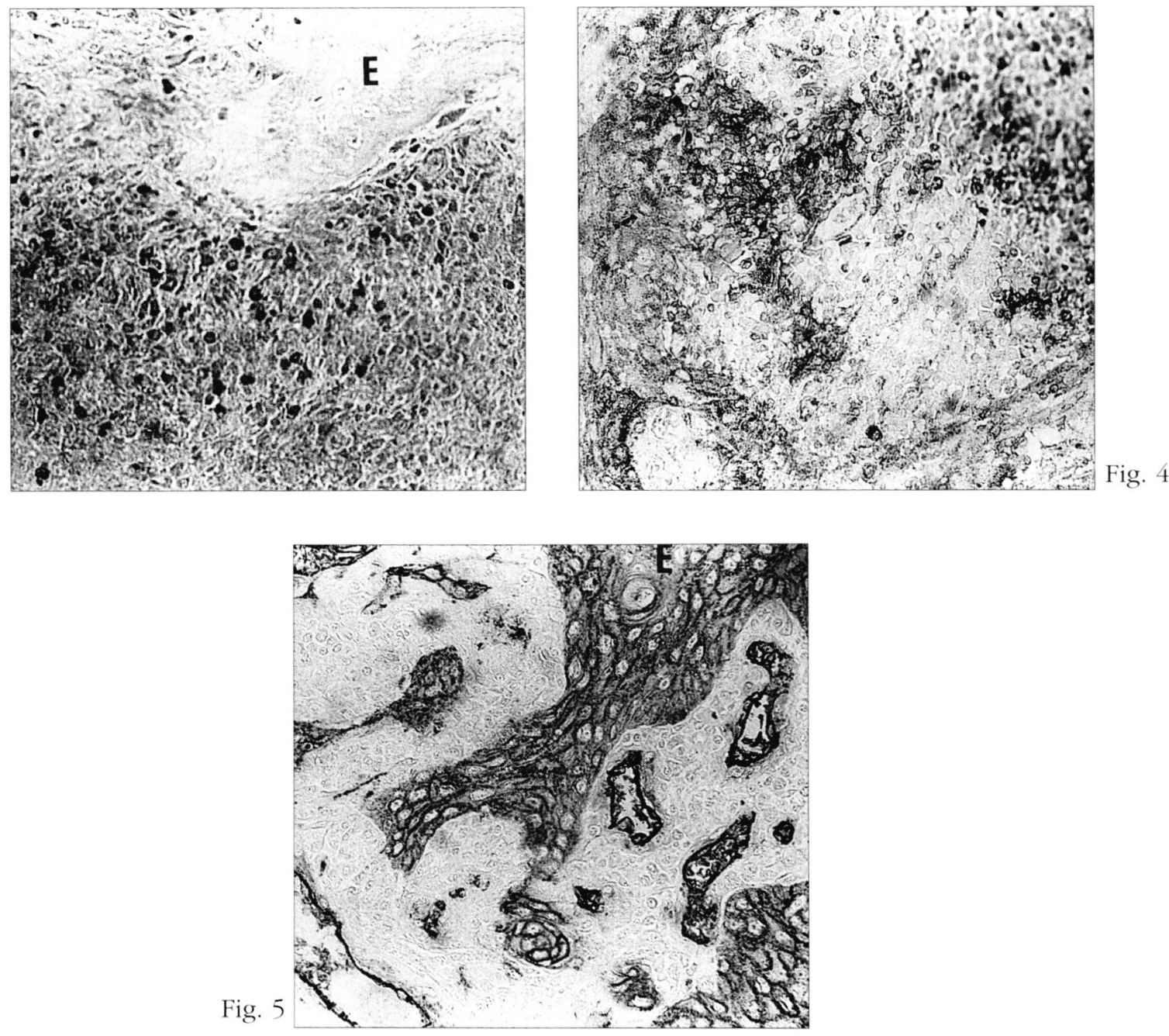

Fig. 1. - Leishmania amastigotes (arrowheads) are sometimes in intracellular localization within macrophages, here immunostained with a CD 68 marker. LSAB $(\times 1000)$

Fig. 2. - A dense inflammatory infiltrate mainly composed of lymphocytes (not stained) and macrophages (KP1 +), in a sub-epithelial (E : epithelium) zone. LSAB $(\times 250)$

Fig. 3. - In the same zone as in Fig. 2, numerous proliferating macrophages (PCNA +) can be observed. E : epithelium. LSAB ( $\times 250$ ).

Fig. 4. - In addition to activated lymphocytes and macrophages (in the inflammatory infiltrate on the right), a positive HLA-DR immunostaining can be observed on epithelial cells (on the left of the section). LSAB $(\times 250)$.

Fig. 5. - The inflammatory foci are highly vascularized, as indicated on this section with the BNH9 marker. E : epithelium. LSAB ( $\times 250)$ 


\section{REFERENCES}

Allardyce R.A. and Bienenstock J. The mucosal immune system in health and disease, with an emphasis on parasitic infections. Bulletin of the World Health Organisation, 1984, 62, 7-25.

Brandtzaeg P. Humoral immune response patterns of human mucosae : induction and relation to bacterial respiratory tract infections. Journal of Infectious Diseases, 1992, 165, 167-176.

Carvalho E.M., Johnson W.D., Barreto E., Marsden P.D., Costa J.L.M., Reed S. and Rocha H. Cell mediated immunity in american cutaneous and mucosal leishmaniasis. Journal of Immunology, 1985, 135, 4144-4148.

Castes M., Agnelli A., Verde O. and Rondon A.J. Characterization of the cellular immune response in american cutaneous leishmaniasis. Clinical Immunology and Immunopathology, 1983, 27, 176-186.

Dimier-David L., Ravisse P., Bustillos R., Rollano F., Mallea F., David C., Lyevre P., Valda L. and Dedet J.P. Histopathologie de la leishmaniose cutanéo-muqueuse Leishmania (Viannia) braziliensis. Annales de Dermatologie-Vénérologie, 1994, 4, 121, 387-392.

Esterre P., Dedet J.P., Guerret S., Chevaller M., Frenay C. and Grimaud J.A. Matrix remodeling and fibroblast phenotype in early lesions of human cutaneous leishmaniasis. Pathology Research and Practice, 1991, 187, 924-930.

Esterre P., Dedet J.P., Frenay C., Chevallier M. and Grimaud J.A. Cell populations in the lesion of human cutaneous leishmaniasis : a light microscopical, immunohistochemical and ultrastructural study. Virchows Archiv A, 1992, 421, 239-247.

Gutierrez Y., Salinas G.H., Palma G., Valderrama L.B., SanTrich C.V. and SARAVIA N.G. Correlation between histopathology, immune response, clinical presentation and evolution in Leishmania braziliensis infection. American Journal of Tropical Medicine and Hygiene, 1991, 45, 281289.

Hellquist H.B., Olsen K.E., Irander K., Karlsson E. and ODKvist L.M. Langerhans cells and subsets of lymphocytes in the nasal mucosa. APMIS, 1991, 99, 449-454.

Huaman J.A. and Castillo M.C. Leishmaniose cutanéomuqueuse. Classification histologique et corrélations anatomocliniques. Archives d'Anatomie et Cytologie Pathologiques, 1990, 38, 135-142.

Juliusson S., Bachert C., Klementsson H., Karlsson G. and PIPKORN U. Macrophage on the nasal mucosal surface in provoked and naturally occuring allergic rhinitis. Acta Otolaryngologica, 1991, 111, 946-963.

Kuper C.F., Koornstra P.J., Hameleers D.M.H., Beiwenga J., Spit B.J., Duijvestjin A.M., Vriesman P.J.C. and Sminia T. The role of nasopharyngeal lymphoid tissue. Immunology Today, 1992, 13, 219-224.

Magalhaes A.V., Moraes M.A.P., Raick A.N., Llanos-Cuentas A., Costa J.M.L., Cuba-Cuba C. and Marsden P.D. Histopatologia de leishmaniose tegumentar por Leishmania braziliensis braziliensis. 1. Padroes histopatologicos e estudo evolutivo das lesoes. Revista de Insti- tuto de Medicina Tropical de Sao Paulo, 1976, 28, 243262.

Marsden P.D. Mucosal leishmaniasis ("espundia"). Transactions of the Royal Society of Tropical Medicine and Hygiene, 1986, 80, 859-876.

Mcghee J.R., Mestecky J., Dertzbaugh H.T., Eldrige J.H., HiRasawa M. and Kiyono H. The mucosal immune system: from fundamental concepts to vaccine development. Vaccine, 1992, 10, 75-88.

Modun R.L., Tapia F.J., Bloom B.R., Gallinoto M.E., Castes M., Rondon A.J., ReA T.H. and Convit J. In situ characterization of the cellular immune response in american cutaneous leishmaniasis. Clinical and Experimental Immunology, 1985, 60, 241-248.

Modlin R.L., Pirmez C., Hofman F.M., Torigian V., Uyemura K., Rea T.H., Bloom B.R. and Brenner M.B. Lymphocytes bearing specific $\gamma \delta$ T-cell receptors accumulate in human infectious disease lesions. Nature, 1989, 339, 544-547.

Pirmez C., Cooper C., Paes-Oliveira M., Schubach A., TORIGIAN V.K. and MODLIN R.L. Immunologic responsiveness in american cutaneous leishmaniasis lesions. Journal of Immunology, 1990, 145, 3100-3104.

RIDLEY D.S. The pathogenesis of cutaneous leishmaniasis. Transactions of the Royal Society of Tropical Medicine and Hygiene, 1979, 73, 150-160.

Ridley D.S., Marsden P.D., Cuba-Cuba C. and Barreto A.C. A histological classification of mucocutaneous leishmaniasis in Brazil and its clinical evaluation. Transactions of the Royal Society of Tropical Medicine and Hygiene, 1980, $74,508-514$.

RIDLEY, D.S. and RIDLEY M.J. The evolution of the lesion in cutaneous leishmaniasis. Journal of Pathology, 1983, 141, 83-96.

Ridley D.S., De Magalhaes A.V. and Marsden P.D. Histological analysis and the pathogenesis of mucocutaneous leishmaniasis. Journal of Pathology, 1989, 159, 293-299.

Sotto M.N., Kanashiro E.H.Y., Matta V.L.R. and Brito T. Cutaneous leishmaniasis of the New World : diagnostic immunopathology and antigen pathways in skin and mucosa. Acta Tropica, 1989, 46, 121-130.

WHO. The control of leishmaniasis. Technical report 793 , 1990.

Wijeyaratne P., Goodman T. and Espinal. C. Leishmaniasis control strategies. Parasitology Today, 1992, 8, 249-250.

Accepté le 26 août 1994 